
This report was prepared as an account of work sponsored by the inited states Government. Neither the United States nor the United states Department of Energy, nor any of their employees, nor any of their contractors, subcontractors, or theic employeds, makes any wartanty, express sr implied, or assumes any leqal liability or cesponsibility for the accuracy, completeness or usefulness of any information, apoaratus, product or process disclosed, or represents that its use rould not infringe privately owned rights.

Princed in the United states of America

Available Erom:

National Technical Information Service

U. \$. Department of Commerce

5285 Port Royal Road

Springfield, virginia $22+61$

Price Printed Copy $\$ \ldots$ _ ; ificrofiche $\$ 4.50$

\section{*Pages}

$1-25$

$25-50$

51-75

$76-100$

$101-125$

$126-150$

$151-175$

i76-200

$201-225$

226-250

$251-275$

276-300

$301-325$

$326-350$

$351-375$

$376-400$

401-425

426-450

$451-475$

$476-500$

500-525

526-550

$551-575$

567-600

NTIS

Selling kice

57.00

$\$ 8.50$

$\$ 10.00$

$\$ 11.50$

$\$ 13.00$

$\$ 14.50$

$\$ 16.00$

$\$ 17.50$

$\$ 19.00$

$\$ 20.50$

$\$ 22.00$

$\$ 23.50$

$\$ 25.00$

\$26. 50

$\$ 28.00$

$\$ 29.50$

$\$ 31.00$

$\$ 32.50$

$\$ 34.00$

$\$ 35.50$

$\$ 37.00$

$\$ 38.50$

$\$ 40.00$

$\$ 41.50$
For dacuments over 600 pages, add $\$ 1.50$ for each additional 25-page increment. 
This tcp:art was prepares ats an acecunt the wirk sponsored by an igency of the Lnited States Guretnman. Neither the lanted Stales fubetsment vor any agency thereof, nor any of their suppoyess, makes any warfents, express or jaijlied, or assumes any legal liability or responsi-

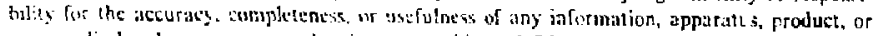

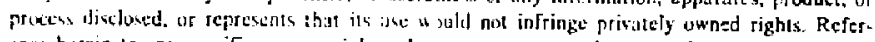

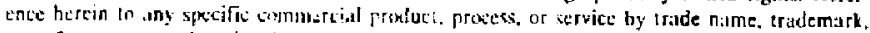
latenufacturer, or olhurkise dies not recessurily a sititute of imply its endorsement, recom. mendation, or lavaring by thi United Stales Ciarernment or any agency thercol. The views and opinions oi authors expresised bercin do gut necessarily state or reflect those of the United Stitcs Goverparnent or anl agtency thereof.

\title{
Fast Current Ramp Experiments on TFTR
}

\author{
E. D. Fredrickson. K. McGuire. R. J. Goldston \\ II. Bell. B. Grek, D. Johnson. A. W. Morris ${ }^{\dagger}$. \\ F. J. Stauffer ${ }^{\ddagger}$, G. Taylor, and M. C. Zarustorff \\ Princeton Plasma Physics Laboratory: \\ Princeton. N.T 08544
}

\begin{abstract}
Electron heat transport on TFTR and other tokamaks is several orders of magnitude larger than neoclassical calculations would predict. Despite considerable effort. there is still no clear theoretical undersiatiding of this anomalous transport. The electron temperature profile, $T_{i}(\mathbf{r})$. shape has shown a marked consistency on many machines, including TFTR. for a wide range of plasma parameters and heating profiles. This could be an important clue as to the process responsible for this enlanced thermal iransport. In this paper we describe what is meant by profile consistency in TFTR and then discuss an experinent which uses a fast current ramp to transient ly decouple the current density profile $J(r)$, and the $T_{t}(r)$ protiles. From this experiment we can determine the influence of $J(r)$ on electron temperature profile consistency.

tPermanent address: Balliol College, Lniversity of Oxford. $\mathrm{CH}^{\mathrm{K}}$

tPermanent address: University of Maryland. College Park. MD
\end{abstract}




\section{Temperature Profile Consistency}

Observations of the consistency of the electron temperature profile have been reported on many machines (TFTR, Alcator, ASDEX, JET, T-10 et c.) $[1-10$. In investigations of profile consistency, the profile shapes have iraditionally been quantified in ternus of the profile peaking parameter. $T_{\epsilon}(0) /\left\langle T_{e}\right\rangle$. This peaking paraneter was found to scale st congly with $g(\sigma)$ [1.2]. The independence of the $T_{e}(r)$ profile shape on the density or density profile shape weakened arguments that pressure-driven electrostatic modes werc responsible for $T_{f}(r)$ profile consistency. Instead. the strong dependence of the peaking parameter on $q(a)$, toget her with the st rong coupling of $T_{t}(r)$ and $J(r)$ through the plasma conductivity, suggested that the current prafile turght have a role in the electron temperature profile consistency. either through tearing modes i1] or through microscopic instabilities 12:. The inherent difficulty of electron temperature profile measurements in tokamaks inade testing of these ideas dificult.

However. it has been realized that nuch of the scaling of the protile pearing parameter is due to the presence of sawtooth oscillations : $T .13$. This dependence of the protile peakedness on the presence of sawteet has been experimentally observed on PLT, ASDEX, and TFTR. In low $q$ discharges where the current protile has been decoupled from the electron temperature (either with LHCD as on Alcator :2!, ASDEX $[14\}$, and PLT 15. or transient (y with a current ratuy as on TFTR) so that sawteeth are absent. the protiles hecome peaked. Further, in high $q(a)$ neutral beam heated discharges (supershots) with strong central convection due to $\mathrm{NB}$ particle deposition [5], the profiles broaden, becoming similar in shape to lower $q(a)$ discharges. While these results contradict the old versions of profile consistency and call into question the role of $J(r)$, they also form 1 be luasis for even st ronger statements of $T_{e}(r)$ profile constancy.

The study of electron temperature profile shapes, available from the multipoint Thomson scattering, ECE radiometer, and Michelson interferonleter diagnostics, on TFTR has supported initial impressions that protile shapes are indeed more constant than known constraints can account for 3-6\%. The shape of the profile out side approxinately $0.4 a$ foutside the sawtooth reconnection region in low $q$ discharges $/$ is found to be nearly invariant over a wide range of density. edge $q$ and neut ral beam heating power. In some cases, the profiles are more consistent with the additional 
restriction that $T_{\varepsilon}>1 \mathrm{keV}$, e.g.. the $0.8 \mathrm{MA}$ ohmic discharges beyond $0 . \mathrm{i} a$.

In these studies. the profile shapes are obtained by first symmetrizing the raw electron temperature profiles to remove Shafranov shift corrections. and then normalizing to the electron temperat ure at the half radius. Vormalizing at the half radius, rather than the center, avoids the confusion int roduced by sawteeth and similar effects. The symmet rization is typically done with a 'slice and stack" method where the Shafranov shift is calculated by assuming the electron temperature is constant on a flux surface. The results from this method agree well wit h the Shafranov shift calculated from 3. the calculated current profile and toroidal effects.

Taking the profile for high $q(a)$ ) ohmic discharges (with very snull sawteeth) as the 'linit' profile (Fig. la), it is found that the profile shaje can be approximately fitted with the function

$$
T_{*}(r) / T_{0}=(1-0.95 r / a)^{2 / 3} E^{-4 r_{i} / 3 a} \text {. }
$$

This function will then be used as a reference shape, not necessarily unique. In discharges with laige central heat loss, e.g. with sawteeth or strong convection due to beam injection. this 'limit' profile shape is flattened in the core. It is this process that Ciaussian profile consistency attempted to model. At the lowest $q(a)$. i.e.. with large sawteeth present. the profiles can be approximately fitted witl the above function or a Gaussian, but at ligher $q(a)$ the profiles clearly differ from the Gaussian form proposed by B. Coppi 12 ?.

$$
T_{e}(r) / T_{0}=\operatorname{erp}-2 q(a) r^{2} / 3 a^{2}:
$$

The constancy of the temperat ure profile shape ontside approximately $0.4 a$ inuplies that the logarithnic derivative of the temperature in this region is also invariant. This may luave some implications for theoretical attempts to underst and the profile conserving mechanism.

In Fig. 1b, the electron temperature profile shapes from high $q(a)$ nteu$1 \mathrm{ral}$ beam heated discharges (co-injection) are compared to the limit profile sliape. The error bars represent the shot to shot vaciation in the profile sluapes for discharges with heating powers from 3.6 to $10.6 \mathrm{MH}$. The Olmic profile is more peaked, but outside of about a/ 3 the profile shape is uncluanged within the experimental accuracy of the $T_{e}(r)$ measurenents (approx. 10\%). Figure 1c shows profile shapes. averaged over three similar shots. for balanced NBI heated discharges (superslıots). The st rongly. 
peaked heatl deposition profile results in large central convective losses $[5,16$ causing a flattened profile. The independence of the profile shape outsicle $a / 3$ on $q(a)$ is seen in Fig. ld where the average profile shape from t]ree similar ohmic $q(a)=2.8$ discharges is compared to the limit profile sluape.

Further evidence that it is the sawteeth that are responsible for flattening $T_{x}(r)$ (not only in the Fadomt sev sense, but on a time average over many sawteeth) within the reconnection region is found during the initial current ramp. For a sliort period of time. as the current diffuses in, $q(0)$ will be greater than one. During this time the $T_{t}(r)$ profile is close to the ideal protile constancy shape, independent of $q(a)$; but when $q(0)$ drops below one, sawtoothing begins and the central portion of the $T_{c}(r)$ profile flattens (Fig. 2).

The recovery of a drastically perturbed $T_{e}(r)$ profile nar be studied during the reheat phase following pellet injection. In Fig. 3 nornalized $T_{f}(r)$ profiles. beginning just before the pellet is injected (pellet injection is at 2.02 seronds 1 , are shown. At 2.03 seconds, the central electron temperat ure lias dropped from approxinately $3.5 \mathrm{keV}$ to $0.8 \mathrm{keV}$, and the profile shape is no longer const ant. But. by 3.0 seconds, the central electron temperat ure has recovered to $2.4 \mathrm{keV}$ and the shape outside of $0.4 a$ is now the limit profle shape.

As illustrated by the above examples, an ascumption of profile constancy describes accurately the shape of $T_{e}(r)$ out sicie of $r / a \approx 0.1$ for full size TF'RR plasmas. These results are consistent with the idea that is varies with the heating profile shape to keep the profile constant. However, detailed transport analysis is recuired to determine the strength of this const raint. These results would also suggest that in a specific discharge the temperature profile shape will resist changes expected from changes in the heating profile. This picture fits nicely with the observed discrepancy bet ween the rate of the heat pulse propagation and the power balance analysis for $v_{e}[17]$. The next section of this paper will discuss experiments in which transient perturbations were used to deteimine the role of the current profile in electron temperature profile consistency. 


\section{Current Profile Consistency}

The observation of profile consistency, coupled with the observed degradation in energy confinement with auxiliary heating (which tends to nodif ${ }^{2}$ the heating profile), suggests that the thernal diffusivity, $x_{e}$, may be a strong function of the temperature profile. This could be a direct dependence of $\gamma_{e}$ on the $T_{e}(r)$ profile, its derivative, or upon related quantities such as the current density, $J_{(r)}$, or $q(r)$. For many tokamaks, these profiles are fairly strongly coupled, naking deternination of the dependence of t. on $T_{e}(r)$ or $f(r)$ or their derivatives difficult. However, in TFTR where the resistive time constant can be several seconds, $T_{\mathrm{e}}(r)$ and the calculated $J(r)$ are not in equilibrium for one or two seconds following the beginning of the current flattop. It is interesting to note that the electron temperature reaches its 'profile consistent' shape before the plasma current profile reaches resistive equilibrium. Figure 2 shows three electron temperature protiles measured during the initial current ramp. The discharge begins sawtoothing at about 1.4 seconds, modifying the central profile shape, but the profiles outside of $r / a \approx 0.4$ are remarkably invariant. Analysis of these discharges has provided useful information on the role of $J(r)$ in profile consistency. Experinents done with fast current ramps luave even more strongiy, if transiently, decoupled the $J(r)$ and $T_{e}(r)$ protiles.

ts nost inferred current jrofiles on TFTR are stable or marginalty at able to low $m$ tearing modes, tearing mode induced transport bas been suggested as a possible explanation for the observed consistency of the $T_{a}(r)$ profile. The irypothesis is that tearing mode stability can depend sensitively on the current profile shape; thus, modes should grow quickly as a result of small perturbations to the $J_{(r)}$ or $T_{\varepsilon}(r)$ profiles, feeding back through enhanced local heat transport to keep $T_{e}(r)$ and hence $J(r)$ stable and. indirectly. consjstent. The current ramp experiments offer the opport muity to test this lypothesis. The discharge was monitored for MHD activity during and following the ramp, and a code was developed to calculate the stability of TFTR current profiles to tearing modes.

Fast current ramps were done both with olnuic and neutral beam heated discliarges. To avoid the problens inherent in analysis of the initial current ramp e.g.. unknown initial $J(r)$, a stable. low current plasua was establisined and allowed to equilibrate for approvinuteiy one second. In the first example (Fig. 4) the plasma current was ramped for 0.25 seconds at at rate 
of $3.2 \mathrm{MA} / \mathrm{sec}$ to a final plasma current of $2.2 \mathrm{MA}$. The initial edge $q$ was about 5.2 which then dropped to 3.3 . While this ramp rate did not result in disruptions, bursts of MHD activity were observed during the ramp as the $q=5,4.5,3$ rational surfaces passed through the edge of the plasma (Fig. 5).

In a second example (Fig. 6). the addition of $6 \mathrm{MW}$ of neutral beam heating coincident with the chirrent ramp resulted in slightly different MHD characterist ics. Rather than the descending seculuence of edge modes, internal $m / n=2 / 1$ and $3 / 1$ modes were destabilized, along with the $m / n=4 / 1$ mode when the $q=4$ surface passed through the edge of the plasmil (Fig. 7). Farter current camps were not possible due to hardware limitations. Ramps at slower rates were not notably different, except. for the absence of the bursts of MHD activity,

Since the purpose of this experiunent was rhe study of plasmas in which $J(r)$ and $T_{e}(r)$ were not in equilibriun, the assumption of classical resistive current diffusion in the calculation of $j(r)$ must be examined. Previous experinents have suggested that the current diffusion can be anomalons at high ramp rates is!. Measurements of the current profile shape are not available yet on TFTR, so for this work the current profiles vere calculated with a tine dependent current diffusion code [19]. These calculations predict the tinse dependent $\Lambda\left(\equiv \beta_{\text {pol }} \div l_{i} / 2\right)$ and location of the $q=1$ surface. These predictions can then be compared to the experimental measurements of these quanitities as a clueck on the current diffusion simula: ion.

The time dependent $A$ is sensitive to the gross current profile shape, but not to details of $J(r)$ in the core region. In the experiment, the measured A overshot the final value, dropping from about 0.9 to 0.55 . below the typical value for a 2.2 MIA plasma of 0.75 . The 1 then recovered with a time constant of about 0.5 sec., reaching a value of $0.75 \mathrm{by}$ the end of the discharge. This result is consistent with the classical resistive current penetration calculatiois which pretict strong skin currents in the plasma edge (Fig. 8a). The location of th $q(r) 1$ surface may be inferred from measurement of the sawtooth inversion radius. The time evolution of the $g(r) 1$ surtace measured in this way was in reasonable agreement with that calculated by the resistive current diffusion code (Fig. 8b). The offset is due to small uncertainties in the $T_{\epsilon}(r)$ protile.

A small edge disruption was observed, coincident with the passage of the $q=1$ surface through the edge of the plasma. This disruption was 
seen experimentally as a short increase in $\lambda$, the presence of an $m_{i} n=4 / 1$ oscillation. and the loss of edge plasma temperature. The $m / n=4 / 1$ mode caused a rapid drop in the edge temperature: at $r=70 \mathrm{~cm}$ (approximately $12 \mathrm{~cm}$ from the limiter) the electron temperature dropped from 500 to 100 $\mathrm{eV}$. This high resistivity region allowed the skin current to diffuse rapidly causing a short increase both in the $A$ experimentally observed and in the current diffusion simulations. Thus the observed MHD activity did not canse measurable anomalous current penet ration, but in this case did enhance the current diffusion by lowering the plasma temperat ure. Bursts of XHD activity were also observed at the passage of the $m / n=5 / 1$ and $9 / 2$ rational surfaces through the plasma edge. These bursts were not observed to affect the current diffusion or plasma temperature. Thus in these discharges low mumber tearing modes apparently affect current penet ration through modification of the $T_{c}(r)$ profile.

The calculated current profiles were also tested for theoretical tearing mode stability with a $\Delta_{m, n}^{\prime}$ code. The code solves the equation

$$
\left(\partial^{2} / \partial r^{2}+1 / r \partial / \partial r\right) t^{i}=\left\{m q R_{o} /\left(r B_{T}(m-n q)\right)(\partial J / \partial r) i\right.
$$

to get the perturbed helical flux function, $\overline{4}(r)$, from which

$$
\Delta_{m, r}^{\prime} \equiv\left((\partial \tilde{v} / \partial r)^{+}-(\partial \tilde{w} / \partial r)^{-}\right) / \dot{i}^{-}
$$

is calculated :20!. Toroidal effects are included to tine extent that $q(r)$ and $J(r)$ are mapped from the toroidal equilibrium code to radial coordinates. The nupping is done by averaging the minor radius over the flux surface to map : to $r$ and averaging $J\left(\psi^{*}, R\right)$ to get $J\left(u^{\circ}\right)$ and thus $J(r)$. Pressure and $D_{R}$ effects [21] are ignored in these calculations. Positive values of $\Delta_{m, n}^{\prime}$ indicate instability and the island width. $\pi$. can be predicted by solving $\Delta^{\prime}\left(u^{\prime}\right)=0$ [??]. The stability calculations were done at each time point, givitrg the stability of each mode, $\Delta_{m, n}^{\prime}(t)$, throughout the shot. The ialculations were done for modes with $m$ in, 1 and in the range $6 \because m \geq 2$.

Comparison of the $3_{m, n}^{\prime}$ calculations with the observed MHD activity during the current ramp in these two examples (Figs. 5 and $T$ ) showed good agreentult. The $\mathcal{S}_{m . n}^{\prime}$ calculations accurately predicted the unstable edge tearing modes. even though this is where the shape of the current protiles is least well known. In addition. the calculations also predicted the instability of the $m: n=2 / 1$ mode at the correct time. but the $m: n=3 ; 1$ mode was 
calculated to be stable (Fig. i). Other modes were calculated to be stable. even for the most strongly perturbed current profiles. These results are suggestive, but it is likely that the calculation of the current density profile is not sufficient ly accurate (and the theory sufficiently incomplete) to make a detailed conparison nueaningful at present.

Measurements of the electron temperature profile throughout the current ramp showed that the $T_{e}(r)$ profile sliape remained relatively constant while the calculated $J(r)$ was strongly modified (Figs. 9a and $9 \mathrm{~b}$ ). The central $T_{c}$ changed on the same time scale as the plasma current. i.e.. about a half second. In the ohmic current ramp experiment, due to the large skin current, the olumic heating power dissipated in the edge $(r: 60 \mathrm{~cm})$ increases by an order of magnitude. However, this results in a change in the total heat Aux through the edge region of only about $50 \%$. This change in the heating profile is too small to be useful in determining the dependence of transport on the heating profile. In the neutral beam lieated cases. the change in the heat Hux due to the change in olmic heating profile was eren less. Calculations of tearing mode stability showed that the current profile, althongh strongly modified, remained predominantly stable to tearing modes. This result was supported qualitatively with the Mirmov coil measurements. Further, while the $4 / 1$ did st.rongly affect transport, the of lier modes had to measurable effect on the temperature profile or current diffusion. The conchusion is that low $m$ reating mode induced trausport plays a minor role in maint aining electron temperal ure consistency.

\section{Summary}

In conclusion. the study of electron temperature profiles on TFTR has disproven some of the old ideas on profile consistency, and suggested a liew form of profile constancy to take its place. Much of the old data on profile consistency can be explained by the effect of sawteeth on the electron temperat ure profile. The above analysis is consistent with a profile conserving mechanism which constrains the profile shape bet ween the saw toothing region and the plasma edge. More detailed radial transport analysis is required to determine how strongly $x_{c}$ responds to changes in the heating profile shape. The electron temperature protile shape outside $0.4 a$ is foumd to be independent of the density and heating profile, as was the case before: 
but, in addition. it is also independent of $q(a)$. A series of fast current ramp experiments were done to investigate the question of whet her it is the $J(r)$ or $T_{\xi}(r)$ profile which is constraized. The results of this experiment shows that the $J(r)$ profile can ise strongly modified, but that $T_{e}(r)$ is constant in the fastion described abo:e.

\section{Acknowledgments}

The authors wori' like to thank H. P. Furth and A. Boozer for many helpful discussions. We would also like to thank the nany TFTR physicists who provideci so much of this excellent data. This work was supported by IS DOE C'ontract No. DE-AC02-76CH03073. 


\section{References}

[1] Taylor, G. et al., Mucl. Fusion 20 (1986) 339.

[2] Knowlton, S., in Proceedings of the Second Workshop on Transport and Profile Consistency in Tolamaks, Lniversity of Maryland, April $1 \mathrm{i}-18,1986$ (unpublished).

(3) Fredrickson, E. et al., Controlled Fusion and Plasma Heating, 13th European Conference (1986) Vol. I, 148, Schliersee, F.R.G.

4. Goldston. R. J. et al., Controlled Fusion and Piasma Heating, 13th European Conference (1986) Vol. 1, 41, Schliersee, F.R.G.

:5! Goldston, R. J. et al., Kyoto 12th International Conference an Plasma Physics and Controlled Thermonuclear Fusion, Kyoto, IAEA-CX$47 / A-I I-1$.

6) Boyd. D. A., Kyoto 12th International Conference on Plasma Plyysics and Cont molled Thermonuclear Fusion. Kyoto, IAEA-C X-AT;AlIt.

:i] Goldston, R. J., Plasina Phys. Controlled Fusion 26 (1984)

¿. Murman. H. et al., Controlled Fusion and Plasma Heating, 13t h Eltropean Conference (1986) Vol. 1, 216. Sclliersee, F.R.G.

:9] Düchs, D. F. et al., 12th International Conference on Plasma Physics and Controlled Thermonuclear Fusion, Kyoto, IAEA-CN-4t/A-II-1-1.

[10] Esiptchuk, Yis. V. and Razumova, K. A., Plasma Plyss. Controlled Fusion 20 (1986) 1253.

[11] Furth, H. P., Plasma Pliys. Controlled Fusion gg (1986) 1305.

[12] Coppi, B., and Tang, W., Princetoll Plasma Physics Laboratory Report PPPL-2151.

[13] Waltz, R. et al. Nucl. Fusion 26 (1986) 17'29.

[14; McCornick, $K$. et al., Controlled Fusion and Plasma Heating, 13th European Conference (1986) Vol. II, 323, Schliersee, F.R.G. 
15. Bernabei, S. et al.. 12th Intemational Conference on Plasma Physics and Controlled Thermonuclear Fusion, Kyoto, IAEA-C.T-4/F-II-1.

[16] Strachan, J. et al.. Plyys. Rev. Lett. (to be published).

[1i] Fredrickson, E. et al., Nucl. Fusion 26 (1986) 849.

[18] Stambaugh. R. et al., Nucl. Fusion 22 (1982) 395.

[19: Hawryluk, R. J., Phys. of Plasmas Close to Thermonuclear Ignition, Varenna 1979 (Vol. 1 ).

20: Furt', H. P., Rutherford, P. H., and Selberg, H., Phys. Fluids 16 (1973) 1054 .

21: Glasser, A. H., Greene, J. M., and Johnson, J. L., Plyys. Fluids 19 (1976) $56 \%$.

22: White, R. B., Monticello. D., Rosenblith, M. N., and Waddell. B. V., Phys. Fluids $\underline{20}(197 i) 804$. 


\section{List of Figures}

Figure Ia. The solid curve is the averaye of two normalized electron temperature profiles from ohmic high $q(a)$ discharges. The profiles heve been mapped to flux surfaces to correct for the Shafranov shift. The dashed curve is a fitting function which approximates the $T_{e}(r)$ profile shapes for TFTR large major radius discharges (22022,22024). The dotted line is the old profile consistency shape, $T_{\epsilon}(r) / T_{\epsilon}(0)=\exp \left(2 q_{a} r^{2}\right) /\left(3 a^{2}\right)$, for $q(a)=\uparrow$. $\left(q_{c y l}(\alpha) \approx 7 .<n_{\mathrm{E}}>\approx 0.8-1.0 \times 10^{19} / \mathrm{m}^{3}, I_{p}=0.8 . \mathrm{M} .4 . B_{T}=4.5 T\right.$. and $\left.T_{e}(0) \approx 3.6-4.2 k_{e} V_{i}\right)$

Figure $1 \mathrm{~b}$. The average of the nomalized profiles from five neut ral beam heated discharges with injected powers from 3.8 to $10.5 \mathrm{MH}$, again conlpared to an approximate limit profile siape (24001-24004,24006) $\left(q_{\mathrm{cy}}(a) \approx\right.$ 7.T. $\therefore n_{e}>=1.1-1.8 \times 10^{19} / \mathrm{m}^{3}, I_{p}=0.8 .4 . B_{T}=4.8 T, T_{e}(0) \approx$ $4-5 k \in \xi i)$

Figure lc. The average of profile shapes from thre's similar ligh $q(a)$

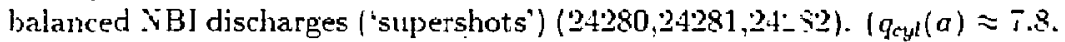
$n_{e}=2.2 \times 10^{19} / \mathrm{m}^{3}, I_{p}=0.8 M A, B_{T}=4.8 T, T_{t}(0) \approx 5.8 \mathrm{ke} \mathrm{F}^{\circ}$ )

Figure 1d. The average of profile shapes from three low $q(a)$ ohnic discharges (24088,24096,24909). $\left(q_{\text {cyl }}(a) \approx 2.9,<n_{\epsilon} .=2.9-5.2 \mathrm{k}\right.$ $\left.10^{19} / \mathrm{m}^{3} . I_{p}=2.2 .1 / \mathrm{A}, B_{T}=4.8 T, T_{\epsilon}(0) \approx 1.8-3.8 \mathrm{kcl}.\right)$

Figure 2. Electron temperature profiles during the current ramp phase of a 2.2 MA plasma. The profiles are from 1.0, 1.5. and 2.0 seconds into the discharge. Sawteeth began at approxinately 1.4 seconds and are presumalsly responsible for the change in profile shape. $\left(q_{c y l}(a)=3.3 .2 .8\right.$. and 2.5 at 1.0. 1.5. and 2.0 seconds, respectively, from shot 12035.)

Figure 3. Somatized electron temperature profiles showing the $T_{8}(r)$ profile shape during the reheat following pellet injection. The times of the profiles are for 2.0 seconds, just before pellet injection. 2.03 seconds. just after injection, and at 3.0 and 3.5 seconds. The electron temperat ure dropped from $3.8 \mathrm{keV}$ on axis at 2.0 secoinds to 0.8 keV at 2.03 seconds with the pellet. injection. (Shot 13640)

Figure 4. Current. density, temperat ure, and loop voltage for an "lmmic current ramp shot. (Shot 17906)

Figure 5a. The envelope of MHD activity during the current ramp shut in Fig. 4. The bursts of MHD activity are identified by mode numbers 
formd from the phase analysis of the poloidal and toroidal arrat of Mirnor coils.

Figure 5̧b. The $\Delta_{m, n}^{\prime}$ 's calculated for the modes observed in Fig. 5a.

Fjgure 6. Current, density, temperature, and loop voltage for a current ramp shot with 6 MIV of NB power. (shot 18741)

Figure $i \mathrm{a}$. The envelope of $\mathrm{HHD}$ activity seen during the neut ral beam heated current ramp in Fig. 6. The NHD behavior is different than in the ohmic case of Fig. 4 .

Figure ib. The calculated $\Delta_{m, n}^{\prime}$ 's for the modes seen in Fig ra. The agreement between experiment and calculation is not as good as in Fig. 5.

Figure 8a. A vs. time, calculated, and measured for the current ramp shot in Fig. 4 .

Figure sb. Approximate sawtootin inversion radius (dots) deterinined from the soft $x$-ray inaging system and the calculated $c_{1}=1$ surface for ahove assuming resistive, neoclassical current diffusion. The chord averaged inversion radii lave been corrected by 1.3 to correct for chord averaging effects. Also plotted is $1 / g(a)$, which is found to approximate the normalized in'version radius in equilibrium.

Figure 9a. Selected calculated current profiles from the $\$ B \mathrm{BI}$ current ramp shot (Fig. 6). For most of the current ramp the $J(r)$ profile is hollow falt bough toroidal effects keep $q(\boldsymbol{r})$ monot onic in "inor radius). The tinues for the profiles are: a - 2.5 sec.. b - 2.7 sec., c - 5.4 sec., $d-3.5$ sec.. aud e -4.0 seconds.

Figure 9b. The nornalized temperature profiles corresponding to the current profiles in Fig. 9a. Despite rather large changes in the current profile, the temperature profile shape remains invariant. The times for the prohiles are as in Fig. 9a. 

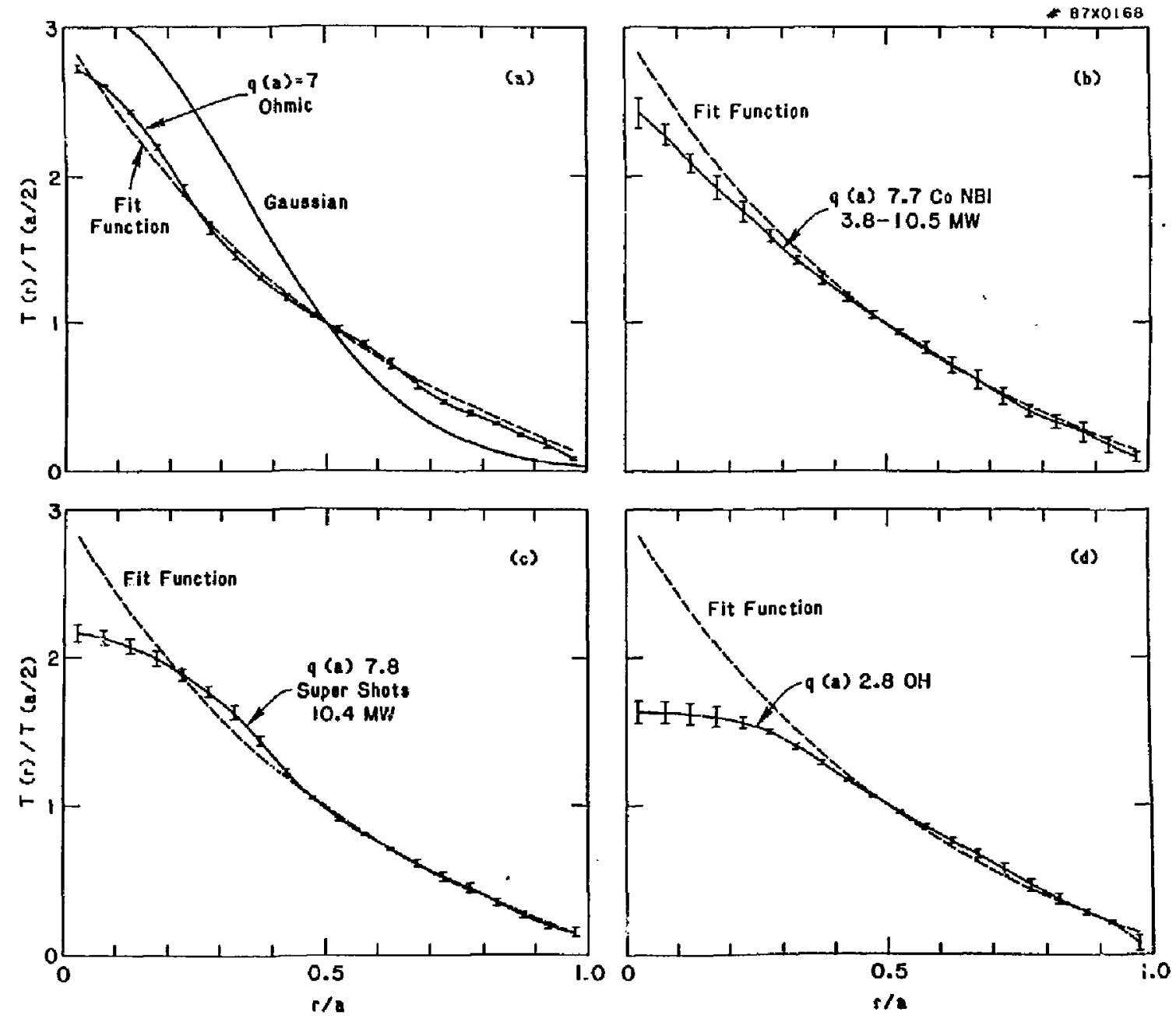

Fig. J (a) - (a) 


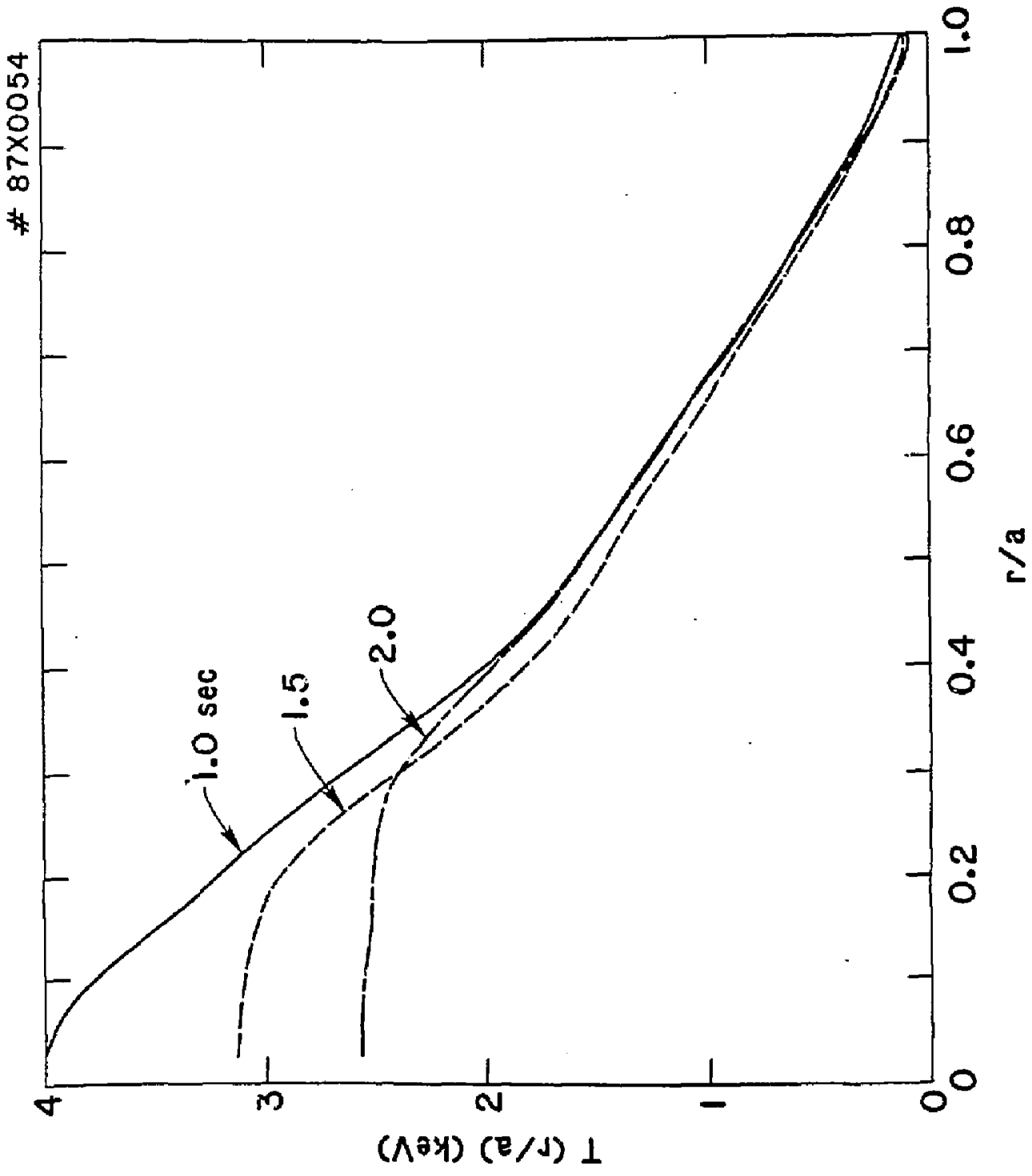




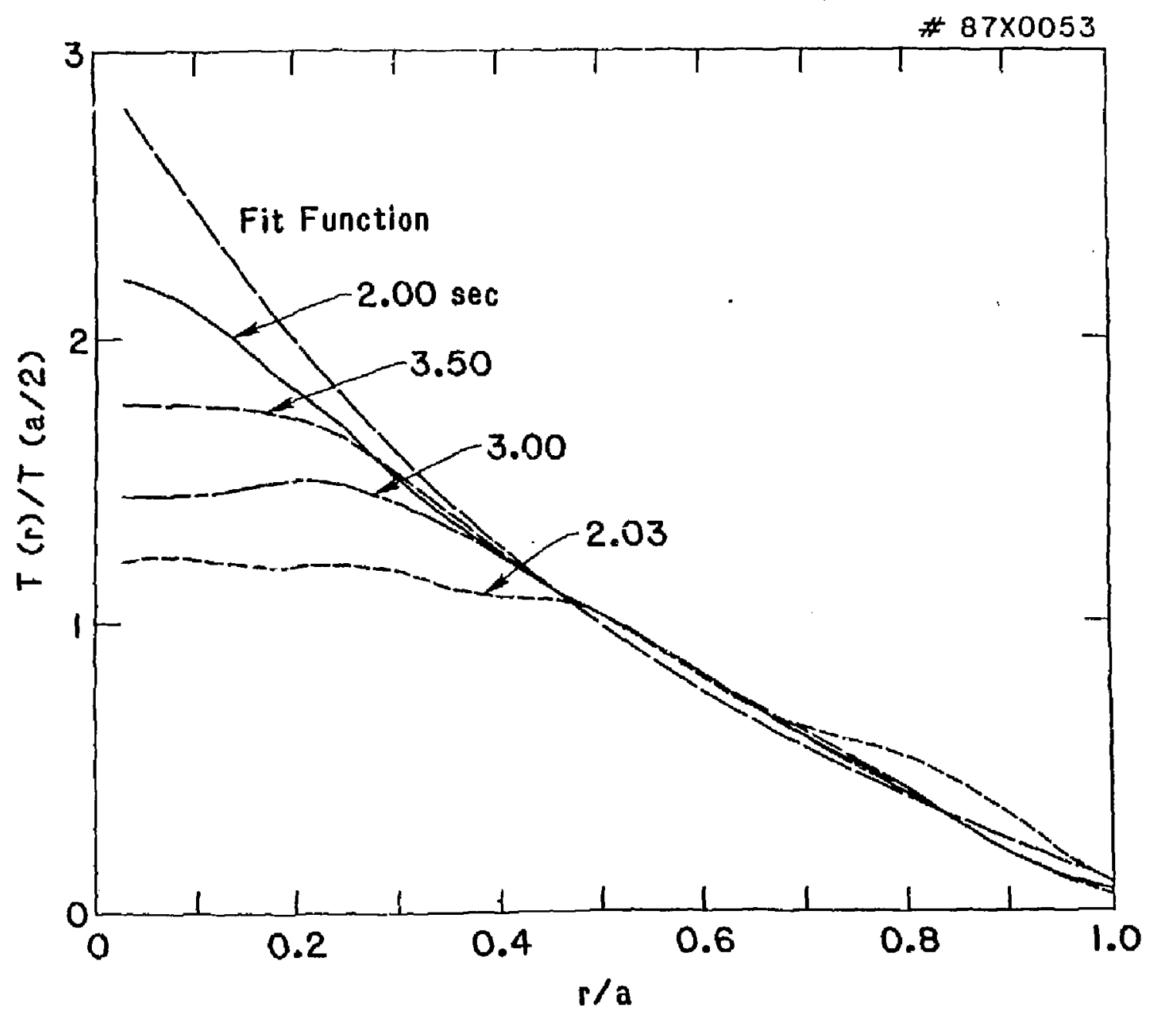

Fig. 3 


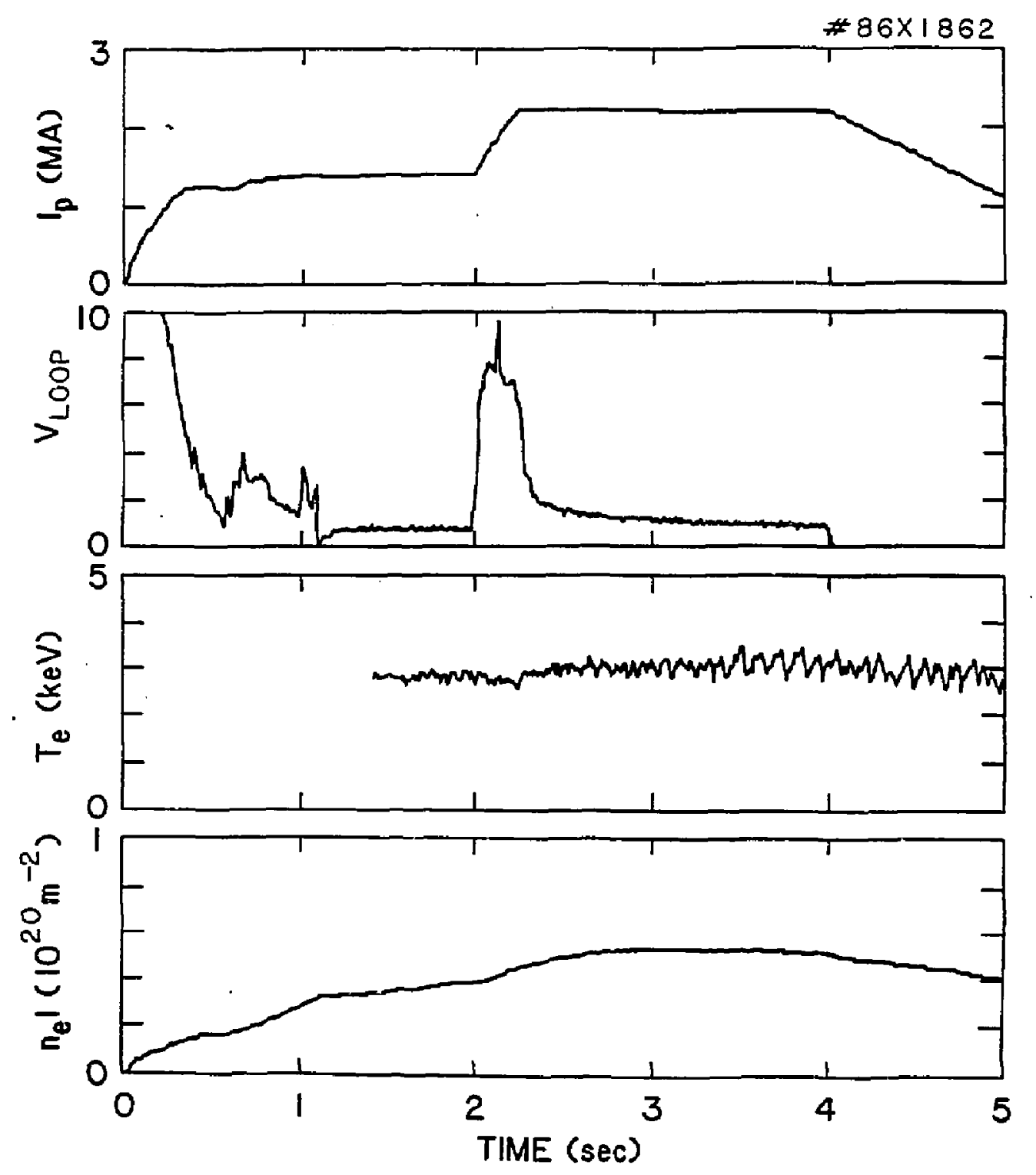

Fig. 4 

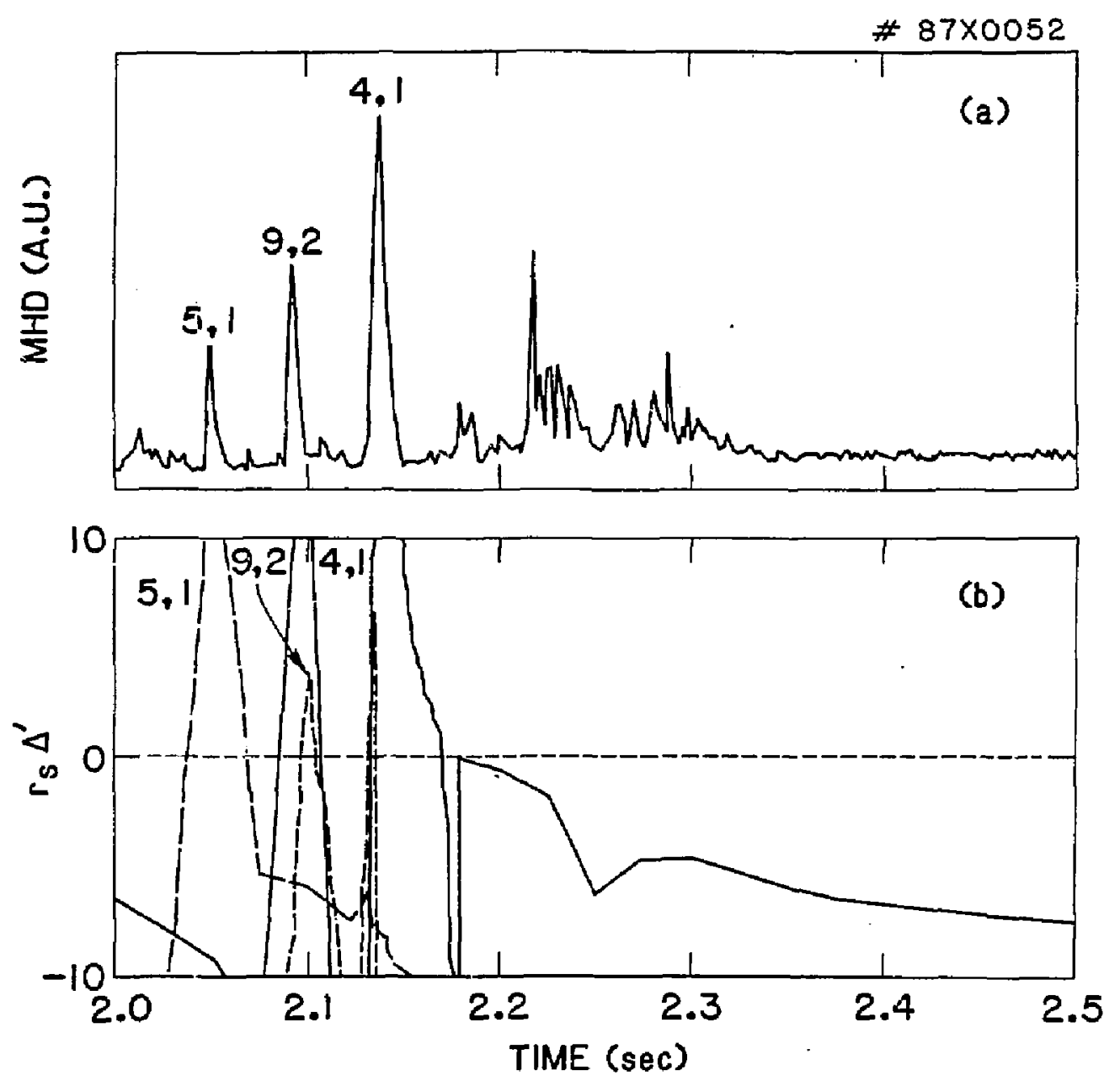

Fig. 5 (a) - (b) 

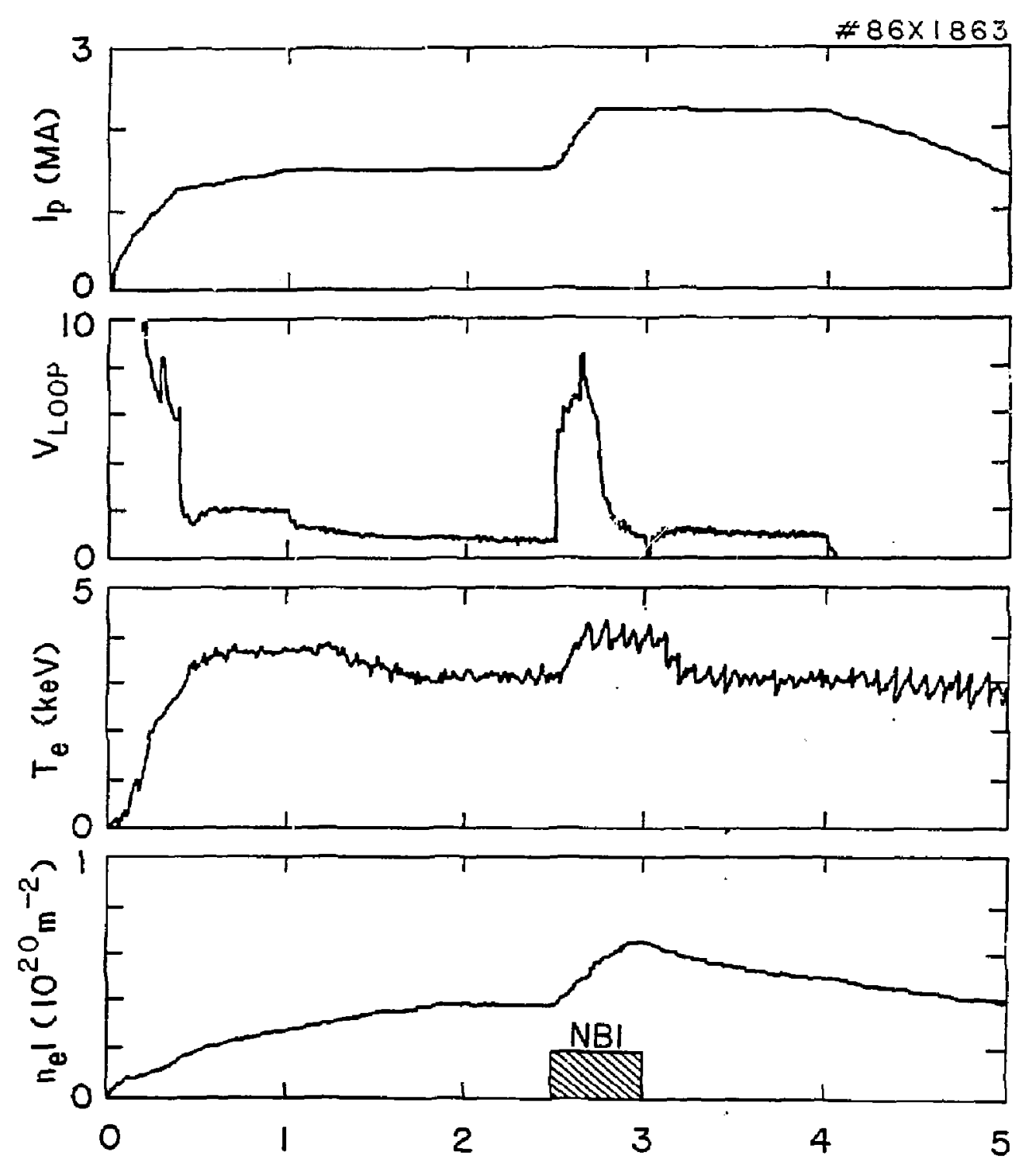

TIME (sec)

Fig. 6 

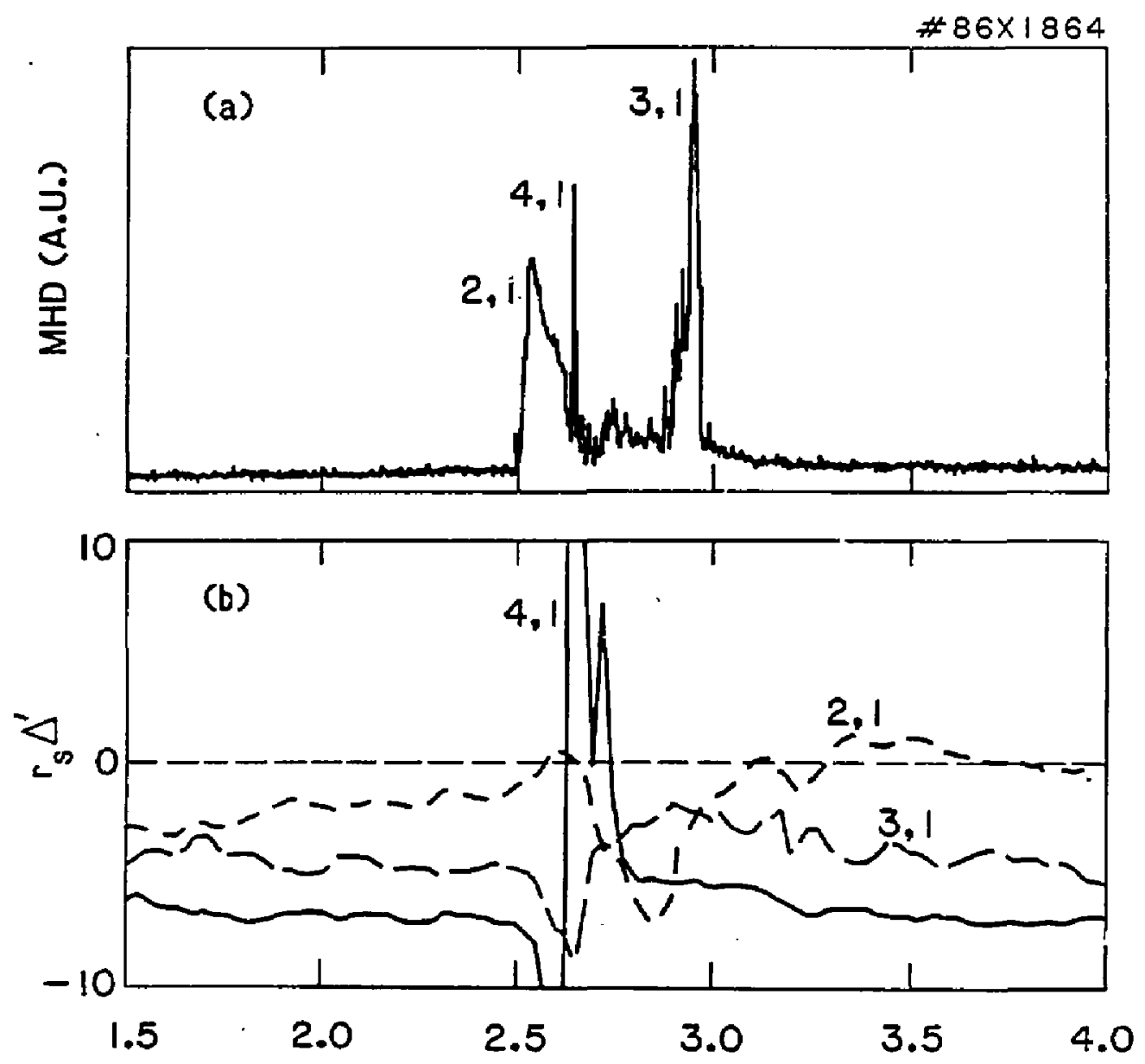

TIME (sec)

Fig. 7 (a) - (b) 


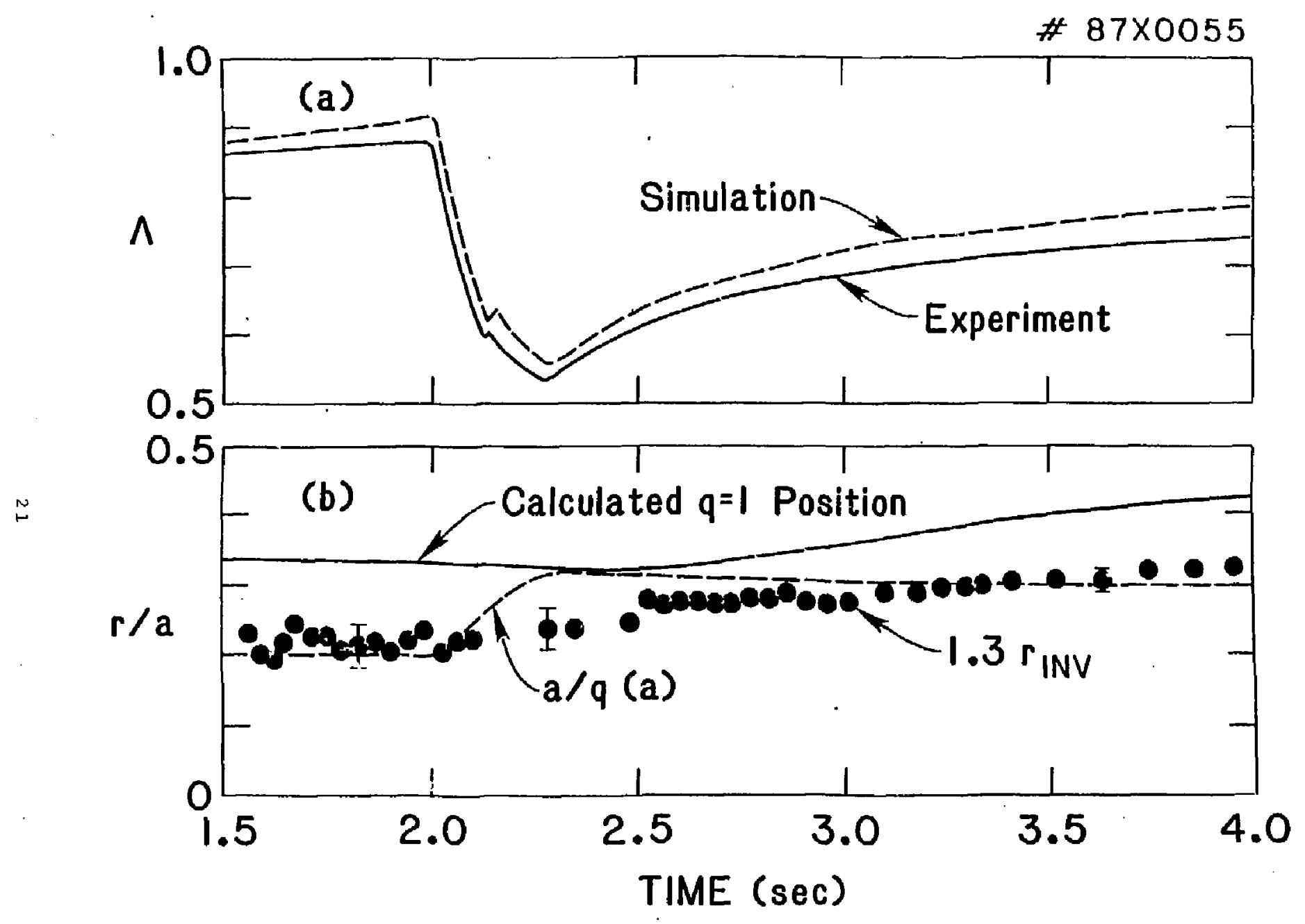

pri.c. $8(a)-(1)$ 


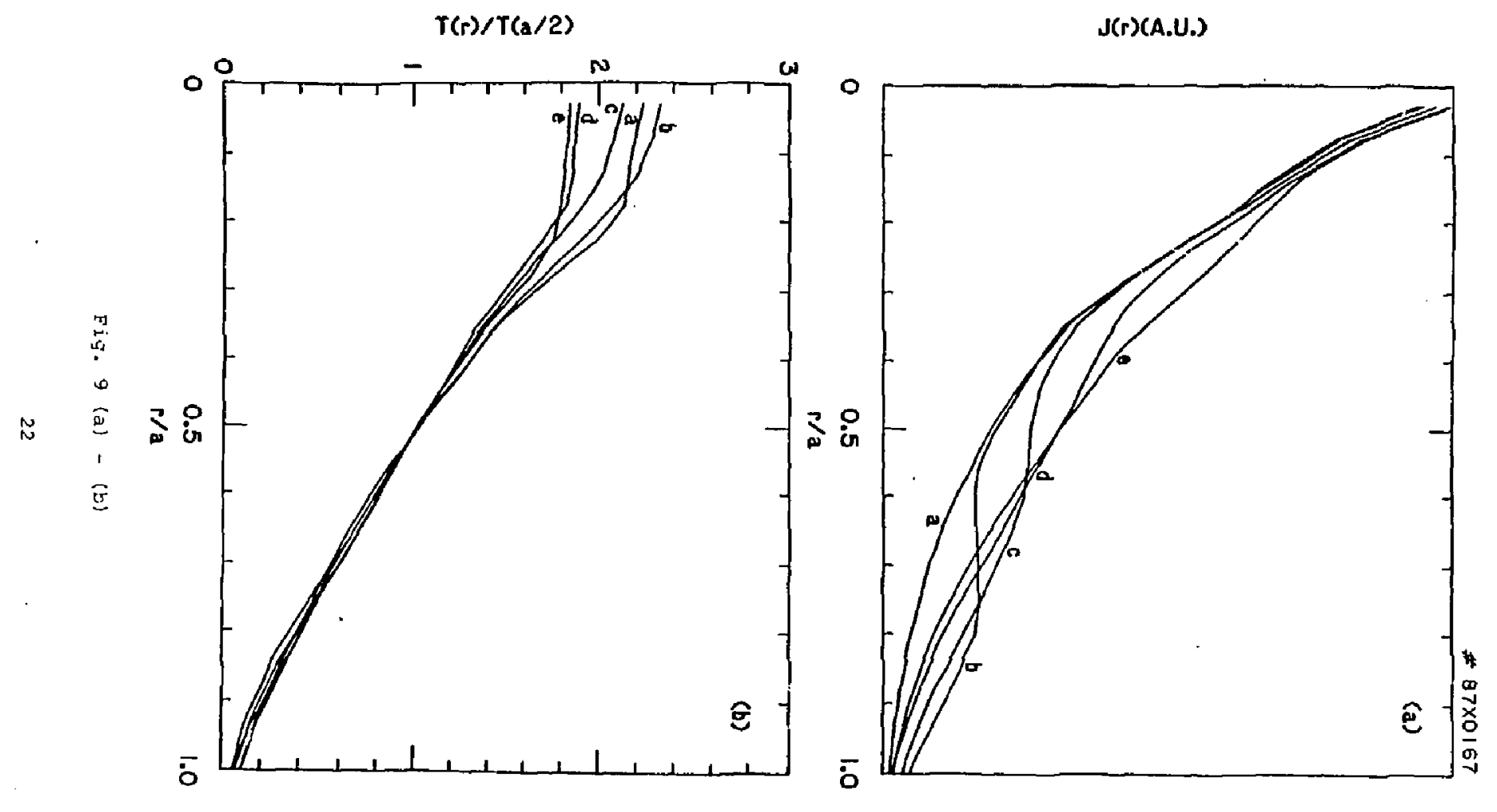


Dr. Frar: $\alpha$ Paolonl, Ualy ot Nol longong, AUSTRALIA

Prot. M,H. Grannan, Univ Sygngy, AUSTRALIA

PIasma Rosearen Lab., Austrolian Nat. UnIV., AUSIRAL 1 A

Prot. I.R. Jories, fIlnders Univ.., australia

Prof. F. Cad, Inst Theo Phys A AUTRIA

Prot. M. Helnder, Instltat fur Theorailsche physik,AUSTRIA

M. Goossens, Astronumlseh InstltuUt, BELGIUM

Ecole Royalo MIIItalra, Lab de Phys Plasmas, BELGIUM

Com. of European, Dg XII Fuslon Prog, BELGIUM

Prof. R. Bowelque, Laboratorium voor Naturkunda, BELGium

Or. P.H. Sakanaka, Univ Estadual, BRAzIL

Instituto De Pasquisas Espaclasi-IIPE, BRAZIL

LIbrary, Atomle Enargy of Canada Limitod, CANADA

Or. M.P. Bachynskl, MPQ Technologlas, Ine., CNNAA

Dr. H.M. Skarsgard, Univ ot Seskateheman, CANAOA

Or. H. Barnard, Unlverslty of Britlst Columbla, GNNOA

Prat. J. Telchmenn, Univ. of Mantreol, CNNAOA

Prof. S.R. Sreeniyasan, University of Calgary, CANNOA

Prof. Tudor W. Jonnston, INRS-Energle, CANAOA

Or. C.R, Jamps, Unly. of Albarta, CANAOA

Dr. Foter Lukec, Komenskeho Univ, CZECHOSLOVAKIA

The Librarian, Cuinom Laboratory, ENGLAND

Mrs. S.A. Hutchlnson, JET Library, EAGLANO

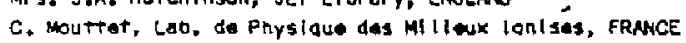

J. Radet, CEN/CADARACHE - Gat SOS, TRANCE

Dr. T.un Mual, Aezdemy al bllographic, HONG KONG

Proprint Library, Cont Ros Inst Phys, HJNGARY

Or. B. Dasgupta, Saha Inst, INDIA

Dr. R.K. Chhajlanl, Yikram Univ. INDIA

Or. P. Kaw, Institute for Plasma Rasaareh, INDIA

Or. PhIllip Rosenay, I srael Inst Tech; ISRAEL

Prof. S. Cugerman. Tel AvIv University, ISRAEL

Llbrarlan, Int'i Ctr thes Phys, ITAly

Prot. G. qostagni. UnIV DI Padova, ITALY

MIss Clella Do Pala, ASSOC EURATOH-ENEA, ITALY

Giblloteca, del ONR EURATCN, ITN,Y

Dr. H. Yamato, Toshlba Ros \& Dev, JAPAN

Prof. I. Kawakami, Atomle Energy Fes. Institute, JAPAN

Prot. Kyol1 NIshikawa, UnIr of HIroshlma, JePN

Direc. Dept+ Lg. Tokemak Res. JAERl, JAPAH

Prot. Sotoshl itoh, Kyushu Unlversity, JAPAY

Research Into Centor, Nagora Unlverslty, JAPAN

Prof. 5. Tanaka, Kyota University, JAPAN

Library, Kyoto Unlversity, JAPAN

Prot. Nobuyuki Incue, Unlversity of Takyo, JAPAN

5. Mor I, JAER!, JAPAN

M.H. KIm, Korea a vanced Energy Research Institute, KOREA

Prot, 0.1. Chol, Adv. Inst sel a Tech, KDREA

Prot. B.5. Llloy, UnIverslty of Walkato, NEW ZEALAND

Instltute of Plosm Physics, PEOPLE'S REPUBLIC OF CHINA

Librarian, Instltute of Phys., PEOPLE'S REPU日LIC OF CHINA

Library, Tsing Hua Univarsity, PEOPLE'S REPU⿴LIC OF CHINA
Z. LI, Soythwest Inst. Physles, PEOPLe's REOUBLIC, F EHIVA Prot. J.A.心. Cabral, Inst Suoerior Tean, PORTUGAi Dr. Oetavlan Petrus, AL I CUzA iniversity, acmak a Or, Johan de Villitars. Plasina Physics. AEC, SO PFRICA Prot, H.A. Hallonrg, Unlvarslty of Natal, SO AFRICA Fusion Dlv. Llbrary, JEN, SPAJN

Dr. Lennart stenflo, Unlvorslty of UMEA, 5HEOEN LIorary, Royal Inst Teen, SWEDEN

Prot. Hans wilhelition, Chalmers UniY Tach, SWEDEN Centro Phys des Plasmas, Ecole Polytach fad, Swhtzealand Bibilotheak, Fon-l nit Voor piacme-Fysloa, THE NETHERLANDS Dr. 0.0. Ryutov, Slberlan Acad Scl, USSR

Dr.G.A. Ellsaev, Kurchator Institute, USSR Dr. V,A. Gtuknikh, I nșt Elactro-Physlcal, USSR Or. V.T. Tolck, Inst, Phys. Tech. USSR

L.-. L.M. Kourlahnykn, Instltute Gen. Physles, USSR Prof. T.J.M. Boyd, UnIv Collogo $N$ wal os, WALES Nuclear Res. Establishmont, Jilleh Lto.., W. GERMANY albilothel., inst. Fur Plasnatorssnung, W. GERMANY Dr. K. Senindler, Ruhr Universitat, W. GERMANY ASOEX Reading Ran. IPD/Max-PI jnck-I nstitut für Plasaghyslk, W. GERMANY Librorlan, Max-planck Institut, W. GERMANY e'rof. ReK. Jenes, Inst Phys, Yugoslayla 